\title{
Point of care diagnostic of hypercoagulability and platelet function in COVID-19 induced acute respiratory distress syndrome: a retrospective observational study
}

Johannes Herrmann ${ }^{1 *}$, Quirin Notz ${ }^{1}$, Tobias Schlesinger ${ }^{1}$, Jan Stumpner ${ }^{1}$, Markus Kredel ${ }^{1}$, Magdalena Sitter ${ }^{1}$, Benedikt Schmid ${ }^{1}$, Peter Kranke ${ }^{1}$, Harald Schulze ${ }^{2}$, Patrick Meybohm ${ }^{1}$ and Christopher Lotz ${ }^{1}$

\begin{abstract}
Background: Coronavirus disease 2019 (COVID-19) associated coagulopathy (CAC) leads to thromboembolic events in a high number of critically ill COVID-19 patients. However, specific diagnostic or therapeutic algorithms for CAC have not been established. In the current study, we analyzed coagulation abnormalities with point-of-care testing (POCT) and their relation to hemostatic complications in patients suffering from COVID-19 induced Acute Respiratory Distress Syndrome (ARDS). Our hypothesis was that specific diagnostic patterns can be identified in patients with COVID-19 induced ARDS at risk of thromboembolic complications utilizing POCT.

Methods: This is a single-center, retrospective observational study. Longitudinal data from 247 rotational thromboelastometries (Rotem ${ }^{\oplus}$ ) and 165 impedance aggregometries (Multiplate ${ }^{\oplus}$ ) were analysed in 18 patients consecutively admitted to the ICU with a COVID-19 induced ARDS between March 12th to June 30th, 2020.

Results: Median age was 61 years (IQR: 51-69). Median $\mathrm{PaO}_{2} / \mathrm{FiO}_{2}$ on admission was $122 \mathrm{mmHg}$ (IQR: 87-189), indicating moderate to severe ARDS. Any form of hemostatic complication occurred in $78 \%$ of the patients with deep vein/arm thrombosis in 39\%, pulmonary embolism in 22\%, and major bleeding in $17 \%$. In Rotem ${ }^{\circledast}$ elevated A10 and maximum clot firmness (MCF) indicated higher clot strength. The delta between EXTEM A10 minus FIBTEM A10 ( $\triangle \mathrm{A} 10)>30 \mathrm{~mm}$, depicting the sole platelet-part of clot firmness, was associated with a higher risk of thromboembolic events (OD: 3.7; 95 \%Cl 1.3-10.3; $p=0.02$ ). Multiplate ${ }^{\circledast}$ aggregometry showed hypoactive platelet function. There was no correlation between single Rotem ${ }^{\circledast}$

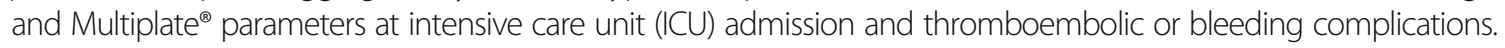

Conclusions: Rotem ${ }^{\oplus}$ and Multiplate ${ }^{\varpi}$ results indicate hypercoagulability and hypoactive platelet dysfunction in COVID-19 induced ARDS but were all in all poorly related to hemostatic complications..

Keywords: COVID-19, Acute Respiratory Distress Syndrome, Point of care testing, Thromboelastometry, Impedance aggregometry

\footnotetext{
*Correspondence: Herrmann_J4@ukw.de

${ }^{1}$ Department of Anesthesiology and Critical Care, University Hospital

Wuerzburg, Oberdürrbacherstr. 6, 97080 Wuerzburg, Germany

Full list of author information is available at the end of the article
}

\section{$\triangle B M C$}

(c) The Author(s). 2021 Open Access This article is licensed under a Creative Commons Attribution 4.0 International License, which permits use, sharing, adaptation, distribution and reproduction in any medium or format, as long as you give appropriate credit to the original author(s) and the source, provide a link to the Creative Commons licence, and indicate if changes were made. The images or other third party material in this article are included in the article's Creative Commons licence, unless indicated otherwise in a credit line to the material. If material is not included in the article's Creative Commons licence and your intended use is not permitted by statutory regulation or exceeds the permitted use, you will need to obtain permission directly from the copyright holder. To view a copy of this licence, visit http://creativecommons.org/licenses/by/4.0/ The Creative Commons Public Domain Dedication waiver (http://creativecommons.org/publicdomain/zero/1.0/) applies to the data made available in this article, unless otherwise stated in a credit line to the data. 


\section{Background}

Hemostatic alterations resulting in severe clinical complications have recently been described in coronavirus disease 2019 (COVID-19) induced acute respiratory distress syndrome (ARDS) [1], [2]. Arterial, venous or microvascular thrombi were found in up to $30 \%$ of COVID-19 intensive care unit (ICU) patients [3]. This COVID-19 associated coagulopathy (CAC) likely differs from sepsis induced disseminated intravascular coagulopathy (DIC). While DIC is early on characterised by a thrombogenic as well as bleeding phenotype, in CAC bleeding events are less common. CAC is associated with increased D-dimer and fibrinogen, as well as elevated cytokine levels accompanied by only minor changes in prothrombin time and platelet count. Pathophysiological mechanisms of CAC include an immunethrombogenic response due to hyperinflammation and concomitant endothelial dysfunction. Little is known about the role of platelets, whereas hyperactive, hypoactive and exhausted platelets have been described [4], [5]. Consumption of coagulation factors, thrombocytopenia and hyperfibrinolysis only appear late in the disease course [6]. Specific anticoagulation algorithms for CAC have not been established and practice patterns vary considerably between prophylactic and therapeutic use of anticoagulants and antithrombotic agents. In line with recommendations of the International Society on Thrombosis and Hemostasis (ISTH) [7] and the American Society of Hematology (ASH) [8], a current review of the Global COVID-19 Thrombosis Collaborative Group recommends parenteral anticoagulation with heparin in hospitalized patients [9], while more than 10 prospective randomized studies are ongoing.

It is likely that platelet reactivity and coagulation abnormalities change during the course of COVID-19 and rapid Point-of-Care testing (POCT) would provide an important tool in order to adjust therapeutic approaches. Thromboelastometry and thromboelastography provide easy to perform bedside tools [10] and their role in DIC from trauma or sepsis is well-established. Thromboelastometry has already been described as a supplementary tool to evaluate and characterize hypercoagulation in COVID-19 [11]. Nevertheless, specific patterns of platelet reactivity or hypercoagulation are not well characterized. In the current study we investigated the use of thromboelastometry and impedance aggregometry in COVID-19 induced ARDS. Our hypothesis was that specific diagnostic patterns can be identified in patients with COVID-19 induced ARDS at risk of thromboembolic complications utilizing POCT.

\section{Methods}

This is a retrospective, observational study conducted at the University Hospital Wuerzburg, including at total of
18 patients consecutively admitted to the ICU with a COVID-19 induced ARDS between March 12th to June 30th, 2020.

All patients had a SARS-CoV2 infection confirmed with real-time reverse transcriptase polymerase chain reaction (RT-PCR) testing based on the recommended World Health Organization standards. The institutional ethic board of the University of Wuerzburg approved the study (63/20). The need for informed consent from individual patients was waived due to the context of sole retrospective chart review within standard care. Routine clinical data including hemostatic complications, laboratory values were recorded using a patient data management system (PDMS) (COPRA6 RM1.0, COPRA System $\mathrm{GmbH}$, Berlin, Germany). Bleeding events were assessed according to definitions by Schulman et al. for major bleedings [12] and Kaatz et al. for clinically relevant non-major bleedings [13]. Hemorrhage was classified as a major bleeding if at least one of the following criteria was fulfilled: (1) Fatal bleeding, (2) Bleeding in a critical area or organ, such as intracranial, intraspinal, intraocular, retroperitoneal, intra-articular or pericardial, or intramuscular with compartment syndrome, (3) Bleeding causing a fall in hemoglobin level of $20 \mathrm{~g} / \mathrm{L}$ or more, leading to transfusion of two or more units of whole blood or red cells. In case a bleeding event did not meet these criteria but did fulfill at least one of the following criteria, it was classified as clinically relevant non-major bleeding: (1) Requiring medical intervention by a healthcare professional, (2) Leading to hospitalization or increased level of care, (3) Prompting a face-to-face evaluation. Thromboembolic events were included in the analysis in case they had been diagnosed by standardized ultrasound examinations or CT scans.

A total of 64 blood samples were analyzed on days 1, 4, 7 , and 14 resulting in data from 247 rotational thromboelastometries and 165 impedance aggregometries. Blood samples were taken from a preexisting arterial line and the following order was used: The first $2.0 \mathrm{~mL}$ blood tube was discarded, followed by drawing a $3.0 \mathrm{~mL}$ plastic tube (polypropylene) containing sodium citrate $0.106 \mathrm{M} / \mathrm{L}$ (1: 10) as anticoagulant (S-Monovette ${ }^{\oplus}$, Sarstedt, Nümbrecht, Germany) and one $1.6 \mathrm{~mL}$ plastic tube (polypropylene) containing 525 antithrombin units/ $\mathrm{mL}$ as anticoagulant (S-Monovette ${ }^{\oplus}$, Sarstedt, Nümbrecht, Germany). To ensure proper mixing of blood with the anticoagulant, three gentle inversions of the tubes were performed. Tubes were stored at room temperature and analyses were performed within $120 \mathrm{~min}$ after blood collection.

Thromboelastometries were conducted on a Rotem ${ }^{\circ}$ delta $\left(\right.$ Rotem $^{\oplus}$, Tem Innovations GmbH, Munich, Germany) from citrate tubes. Impedance aggregometries were performed on a Multiplate ${ }^{\varpi}$ analyzer (Roche Diagnostics $\mathrm{GmbH}$, Mannheim, Germany) from hirudin 
tubes. Rotem ${ }^{\circ}$ analysis was conducted at $37^{\circ} \mathrm{C}$ and comprised out of INTEM, EXTEM, FIBTEM and HEPTEM measuring clotting time (CT), clot formation time (CFT), amplitude 10 and $30 \mathrm{~min}$ after CT (A10/A30), maximum clot firmness (MCF), lysis index $30 \mathrm{~min}, 45$ and $60 \mathrm{~min}$ after CT (LI30/LI45/LI60), maximum lysis $(\mathrm{ML})$ and alpha-angle $(\alpha)$ respectively. Multiplate ${ }^{\circ}$ platelet aggregation was detected at room temperature using thrombin receptor activator peptide 6 (TRAP-6) (final concentration: $32 \mu \mathrm{M}$ ), adenosine diphosphate (ADP) (final concentration: $6.5 \mu \mathrm{M}$ ) and arachidonic acid (ASPI) (final concentration: $0.5 \mu \mathrm{M}$ ), respectively.

Data are reported as median and interquartile range (IQR: $25-75 \%)$. The $\mathrm{Chi}^{2}$-Test and Fisher exact test were used to test the association of dichotomous variables (thromboembolic and bleeding events). A p-value $<0.05$ was considered as statistically significant. Correlation coefficient was calculated according to Spearman $\left(r_{s}\right)$. Data were analyzed by Prism 8.4.3 (GraphPad Software, San Diego, CA) for Microsoft Windows.

\section{Results}

\section{Patient and Clinical Characteristics}

Clinical characteristics and laboratory values are shown in Table 1 . The majority of patients were male (67\%). Median age was 61 years (IQR: 51-69) and median BMI was 29.3 (IQR: 25.3-34.6). None of the patients suffered from malignant disease or chemotherapy, had prior inherent or pre-existing coagulation defects or platelet dysfunctions and no pregnancies were reported.

Prior to ICU admission, three patients received nonsteroidal anti-inflammatory drugs (NSAID) (two acetylsalicylic acid (ASA) and one ibuprofen) in their long-term medication. One of these patients, as well as additional two patients received direct Factor Xa inhibitors, respectively. During ICU treament, all patients received therapeutic, weight-adjusted anticoagulation with unfractionated heparin (UFH) or low molecular weight heparin (LMWH), respectively. Moreover, 15 patients were co-treated with prophylactic doses of ASA. All patients had critical illness as evident by a Sequential Organ Failure Assessment (SOFA) Score on admission of 12 (IQR: 10-15) and Acute Physiology And Chronic Health Evaluation II (APACHE II) Score of 32 (IQR: 25-35). Vasopressor support was required in all patients and $12(67 \%)$ needed renal replacement therapy due to acute renal failure. Pulmonary function was severely impaired with a median $\mathrm{PaO}_{2} / \mathrm{FiO}_{2}$ of 122 (IQR: 87-189) $\mathrm{mmHg}$, indicating moderate to severe ARDS. Due to ARDS progression 10 patients (56\%) were treated with venovenous extracorporeal membrane oxygenation (vv-ECMO).

Thrombotic events and bleeding complications are shown in Table 2. The majority of patients $(78 \%)$ suffered from relevant complications with any form of bleeding in $56 \%$ and thromboembolic events in half of the patients. In total, 2.4 events per patient were recorded.

\section{Point-of-Care Testing}

Point-of-Care testing by Rotem ${ }^{\odot}$ and Multiplate ${ }^{\odot}$ over the course of ICU therapy are depicted in Table 3. Rotem ${ }^{\circ}$ showed a regular propagation phase of clot formation (i.e. normal CT in INTEM and CFT in INTEM and EXTEM, slightly elevated CFT in EXTEM). LI30 in EXTEM and INTEM were within the normal reference range. We found higher clot strength via elevated A10 and MCF in INTEM, EXTEM and FIBTEM. The sole platelet-part of clot firmness is depicted by the delta between EXTEM minus FIBTEM (expressed as $\triangle \mathrm{A} 10$ and $\triangle \mathrm{MCF}$ ). $\triangle \mathrm{A} 10$ and $\triangle \mathrm{MCF}$ slightly decreased during day 1 to day 4 ( $\triangle \mathrm{A} 10)$ and day 1 to day 7 $(\triangle \mathrm{MCF})$. Both values recovered on day 14 . At the same time, FIBTEM-A10 and FIBTEM-MCF increased from day 1 to day 7. There was no correlation between platelet count or mean platelet volume and the observed $\triangle \mathrm{A} 10$ and $\triangle \mathrm{MCF}$, respectively (Fig. $1 \mathrm{a}$ and b). Multiplate ${ }^{\bullet}$ point-of-care testing using agonists TRAP-6, ADP and ASPI detected platelet aggregation well below the respective reference ranges (Fig. $1 \mathrm{c}$ and d). There were no significant differences between ECMO and non-ECMO patients for agonists TRAP-6, ADP and ASPI (data not shown). An example of Rotem ${ }^{\circ}$ measurements in COVID-19 ARDS versus a healthy control is depicted in Fig. 2.

There was no correlation between the results of Pointof-Care testing on day 1 and thromboembolic events or bleeding complications. Taking data from the entire course of ICU therapy into account, thromboembolic events were significantly more frequent if $\Delta \mathrm{A} 10$ exceeded $30 \mathrm{~mm}$ (OD: 3.7; $95 \% \mathrm{CI} 1.3-10.3 ; p=0.02$ ). Bleeding events were less likely if the EXTEM MCF exceeded the upper reference window $(72 \mathrm{~mm}$ ) (OD 3.9, 95 \%CI 1.1-11.9; $\mathrm{p}=0.046)$. LI30 in EXTEM and INTE $\mathrm{M}$ was within their reference range.

\section{Discussion}

Severe cases of COVID-19 requiring intensive care are more likely to suffer from CAC, whereas the early identification of patients at risk remains an unresolved question. In the current study, the majority of patients suffered from relevant complications with any form of bleeding in $56 \%$ and thromboembolic events in $50 \%$. Although the majority of bleeding events was not life threatening, previous publications described a lower incidence of around $5 \%$ [14], [15]. This difference might be caused by a high percentage of ECMO therapy in our study population, which per se is associated with an increased risk of bleeding in COVID-19 [16] and nonCOVID-19 patients [17]. The observed high rate of deep vein/arm thrombosis (39\%) and pulmonary embolism $(22 \%)$ is actually in line with prior publications reporting 
Table 1 Clinical characterization and laboratory values of ICU patients $(n=18)$

\begin{tabular}{|c|c|c|c|c|c|}
\hline Parameters & day 1 & day 4 & day 7 & day 14 & ICU stay \\
\hline Age [years] & & & & & $61(51-69)$ \\
\hline Body mass index $\left[\mathrm{kg} / \mathrm{m}^{2}\right]$ & & & & & $\begin{array}{l}29.3(25.3- \\
34.6)\end{array}$ \\
\hline Duration of ICU stay [days] & & & & & $23(14-34)$ \\
\hline Duration of mechanical ventilation [days] & & & & & $19(11-30)$ \\
\hline 90-day survival [\%] & & & & & 72.2 \\
\hline SOFA (0-24) & $12(10-15)$ & $16(12-18)$ & $15(10-16)$ & $12(5-16)$ & \\
\hline APACHE II (0-71) & $32(25-36)$ & $34(26-39)$ & $32(29-38)$ & $31(23-36)$ & \\
\hline $\mathrm{PaO}_{2} / \mathrm{FiO}_{2}[\mathrm{mmHg}]$ & $122(87-189)$ & $102(89-158)$ & $138(106-167)$ & $149(132-198)$ & \\
\hline White blood count $\left[10^{3} / \mu \mid\right](5-10)$ & $9.2(6.6-11.3)$ & $10.7(7.7-16.1)$ & $11.9(7.4-16.3)$ & $11.1(10.0-15.8)$ & \\
\hline Red blood count $\left[10^{6} / \mu \mid\right](4-6)$ & $3.58(3.14-3.81)$ & $3.11(2.91-3.45)$ & $3.21(2.91-3.28)$ & $3.02(2.74-3.30)$ & \\
\hline $\begin{array}{l}\text { Hemoglobin [g/dl] (female: } 12-16 \text {, male: } \\
\text { 14-18) }\end{array}$ & $10.0(8.9-11.1)$ & $9.1(8.3-10.0)$ & $9.0(8.6-9.2)$ & $9.2(8.5-9.4)$ & \\
\hline Hematocrit [\%] (female: 35-47, male: 42-50) & $32.4(28.3-33.8)$ & $29.0(26.2-31.1)$ & $29.9(27.2-30.5)$ & $27.5(26.0-30.1)$ & \\
\hline Platelet count $\left[10^{3} / \mu \mid\right](150-450)$ & $211(131-282)$ & $206(145-232)$ & $232(165-340)$ & $261(181-328)$ & \\
\hline Mean platelet volume [fl] $(9.7-11.9)$ & $11.0(10.3-11.8)$ & $11.1(10.6-11.5)$ & $11.5(11.2-12.0)$ & $11.8(11.1-13.1)$ & \\
\hline aPTT [sec] (23-36) & $39.6(37.5-46.2)$ & $46.4(40.2-56.6)$ & $50.6(32.9-58.2)$ & $42.5(31.3-54.1)$ & \\
\hline PT [sec] $(10-12)(n=17)$ & $11.9(10.1-12.4)$ & $11.9(10.2-12.2)$ & $11.2(10.2-12.0)$ & $11.8(10.5-12.3)$ & \\
\hline INR $(0,85-1,18)$ & $0.99(0.94-1.06)$ & $1.01(0.94-1.06)$ & $0.98(0.93-1.04)$ & $1.04(0.99-1.08)$ & \\
\hline Quick [\%] (70-130) & $94(88-112)$ & $94(86-113)$ & $103(92-118)$ & $100(88-108)$ & \\
\hline Fibrinogen [g/l] (2.1-4.0) & $6.0(5.5-7.2)$ & $6.5(5.7-7.5)$ & $6.1(4.8-8.4)$ & $5.6(5.0-6.9)$ & \\
\hline D-dimer [mg/l] $(<0.5)$ & $4.7(2.6-7.3)$ & $2.9(1.7-5.4)$ & $4.5(2.3-8.6)$ & $7.2(4.5-11.4)$ & \\
\hline AT [\%] (75-125\%) & 79 (73-90) & $91(79-103)$ & $106(87-119)$ & $96(77-108)$ & \\
\hline DIC Score $(n=17)$ & $3(3-3)$ & $3(2-3)$ & $3(3-3)$ & $3(3-3)$ & \\
\hline IL-6 [pg/ml] $(<7)$ & $224(127-511)$ & $247(81-547)$ & $101(27-212)$ & $74(37-308)$ & \\
\hline C-reactive protein $[\mathrm{mg} / \mathrm{dl}](<0.5)$ & $23.3(16.1-27.7)$ & $25.14(14.3-32.5)$ & $18.8(7.7-29.1)$ & $13.4(7.7-17.5)$ & \\
\hline Procalcitonin [ng/ml] $(<0.5)$ & $1.53(0.72-3.62)$ & $1.85(0.50-6.27)$ & $1.45(0.39-3.86)$ & $1.83(0.27-2.32)$ & \\
\hline Creatinine $[\mathrm{mg} / \mathrm{dl}](<1.17)$ & $1.08(0.80-1.85)$ & $1.08(0.80-1.85)$ & $1.24(0.81-2.02)$ & $1.06(0.86-1.58)$ & \\
\hline Anti-Xa level [IU/mL] & $\begin{array}{l}0.46(0.13-0.78)(n= \\
2)\end{array}$ & $\begin{array}{l}0.38(0.21-0.55)(n= \\
5)\end{array}$ & $\begin{array}{l}0.46(0.32-0.60)(n= \\
7)\end{array}$ & $\begin{array}{l}0.59(0.37-0.76)(n= \\
\text { 4) }\end{array}$ & \\
\hline
\end{tabular}

Clinical characterization and laboratory values of ICU patients (total $n=18$ ) in course of ICU stay.

Clinical scores and laboratory values at days 1, 4, 7 and 14 after admission to ICU. Values are expressed as median and IQR. Disseminated Intravascular Coagulation (DIC) scores are calculated from platelet count, prothrombin time, fibrinogen and D-dimers according to guidelines of the International Society on Thrombosis and Haemostasis (ISTH) [35]. Units are displayed in square brackets and reference values in round brackets. Abbreviations: SOFA Sequential Organ Failure Assessment Score, APACHE II Acute Physiology And Chronic Health Evaluation Score II, $\mathrm{PaO}_{2}$ oxygen partial pressure, FiO ${ }_{2}$ fraction of inspired oxygen, aPTT activated Partial Thromboplastin Time, PT Prothrombin Time, INR International Normalized Ratio, AT Antithrombin, IL-6 Interleukin 6.

venous thrombosis in $27 \%$ [2] and pulmonary embolism in $16.7 \%$ [14] of ICU patients.

Laboratory findings showed a robust increase in Ddimer and fibrinogen levels pinpointing towards the presence of CAC [3]. Platelet counts and mean platelet volumes were almost within their normal range or only slightly increased during the observation period. In large part, the same applied to specific local coagulation tests (International Normalized Ratio (INR), activated partial thromboplastin time (aPTT)), respectively. Mild thrombocytopenia has been frequently observed in patients with COVID-19 and lower nadir platelet counts were associated with increased risk of in-hospital mortality [18]. Meta-analyses indicated that COVID-19 disease progression is associated with lower platelet counts [19] and that thrombocytopenia might be useful for risk stratification [20], [21]. However, the included studies used variable definitions of disease severity. Moreover, elevated platelet counts in severe COVID-19 were also observed [22]. These could be an indicator of a cytokine storm. As such, both an increase and decrease in platelet counts may be a marker of inflammation [23]. Increased fibrinogen levels depict the acute phase response and may also be an important marker of COVID-19 
Table 2 Clinical signs of hemostatic alterations $(n=18)$

\begin{tabular}{lclcc}
\hline Parameters & $\begin{array}{l}\text { Number of patients } \\
\text { affected }\end{array}$ & $\begin{array}{l}\text { Percentage of patients affected } \\
(\boldsymbol{n}=\mathbf{1 8} \text { total) }\end{array}$ & $\begin{array}{l}\text { Number of } \\
\text { events total }\end{array}$ & $\begin{array}{l}\text { Arithmetic mean of events } \\
\text { per patient }\end{array}$ \\
\hline $\begin{array}{l}\text { Any form of hemostatic } \\
\text { complication }\end{array}$ & 14 & $78 \%$ & 34 & 2.4 \\
$\begin{array}{l}\text { No evidence of hemostatic } \\
\text { complication }\end{array}$ & 4 & $22 \%$ & & \\
Any form of bleeding event & & & 15 & 1 \\
Major bleeding & 10 & $56 \%$ & 12 & 1.5 \\
Clinically relevant non-major & 3 & $17 \%$ & & 1.0 \\
bleeding & 8 & $44 \%$ & 19 & 1.2 \\
Any form of thromboembolic & & & 6 & 2.1 \\
event & 9 & $50 \%$ & & 1.1 \\
$\begin{array}{l}\text { Deep vein/arm thrombosis } \\
\text { Pulmonary embolism }\end{array}$ & 7 & $39 \%$ & & 1.5 \\
\hline
\end{tabular}

Clinical signs of hemostatic alterations (total $n=18$ ) in course of ICU stay.

Hemostatic complications comprising bleeding events and thromboembolic events during intensive care for COVID-19. Bleeding events were assessed according to definitions by Schulman et al. [12] and Kaatz et al. [13]. Within the major bleeding group two patients had intracranial bleeding and one patient developed an extensive subcutaneous hematoma after central venous catheter placement. Thromboembolic events were included in the analysis in case they had been diagnosed by standardized ultrasound examinations or CT scans.

coagulation abnormalities. Elevated fibrinogen levels can be found during initial phase of COVID-19, whereas higher levels are associated with increasing disease severity [24], [14]. As platelets and fibrinogen closely interact in the coagulation cascade, preliminary data indicate that increased mean platelet volumes could increase platelet fibrinogen binding and increased hemostatic potential in severe COVID-19 [25]. Our results in life-threatening illness due to moderate to severe COVID-19 ARDS with high SOFA scores are in accordance with previous publications [6]. Although median platelet counts were within normal range during course of ICU stay, non survivors suffered from more pronounced thrombocytopenia and hyperfibrinogenemia (data not shown).

However, none of the parameters are specific for CAC. In particular increased D-dimers have also been associated with higher incidences of critical illness, thrombosis and acute kidney injury [26].

Table 3 Rotem $^{\oplus}$ and Multiplate ${ }^{\oplus}$ results in ICU patients (total $n=18$ )

\begin{tabular}{|c|c|c|c|c|}
\hline Parameters & day 1 & day 4 & day 7 & day 14 \\
\hline $\begin{array}{l}\text { Rotem }^{\circledast} \text { INTEM } \\
\text { CT [s] (100-240) } \\
\text { CFT [s] (30-110) } \\
\text { A10 [mm] (44-66) } \\
\text { MCF [mm] (50-72) } \\
\text { LI30 [\%] }(94-100)\end{array}$ & $\begin{array}{l}207(180-292) \\
62(44-75) \\
70(61-75) \\
75(66-79) \\
100(99-100)\end{array}$ & $\begin{array}{l}273(206-366) \\
59(42-108) \\
69(64-75) \\
75(72-79) \\
100(99-100)\end{array}$ & $\begin{array}{l}242(203-297) \\
45(41-76) \\
71(65-76) \\
77(70-79) \\
100(100-100)\end{array}$ & $\begin{array}{l}229(186-326) \\
43(36-59) \\
72(67-77) \\
76(72-82) \\
100(100-100)\end{array}$ \\
\hline $\begin{array}{l}\text { Rotem }^{\oplus} \text { EXTEM } \\
\text { CT [s] (38-79) } \\
\text { CFT [s] (34-159) } \\
\text { A10 [mm] (43-65) } \\
\text { MCF [mm] (50-72) } \\
\text { LI30 [\%] (94-100) }\end{array}$ & $\begin{array}{l}85(77-97) \\
48(43-59) \\
70(62-76) \\
76(71-80) \\
100(99-100)\end{array}$ & $\begin{array}{l}87(73-98) \\
49(39-69) \\
70(65-75) \\
76(72-78) \\
100(100-100)\end{array}$ & $\begin{array}{l}79(70-85) \\
39(35-61) \\
71(66-77) \\
76(72-80) \\
100(100-100)\end{array}$ & $\begin{array}{l}79(71-84) \\
37(27-56) \\
72(67-77) \\
77(73-81) \\
100(99-100)\end{array}$ \\
\hline $\begin{array}{l}\text { Rotem }{ }^{\oplus} \text { FIBTEM } \\
\text { A10 [mm] (7-23) } \\
\text { MCF [mm] }(9-25)\end{array}$ & $\begin{array}{l}38(31-42) \\
39(35-45)\end{array}$ & $\begin{array}{l}42(32-52) \\
46(36-54)\end{array}$ & $\begin{array}{l}45(34-55) \\
51(36-61)\end{array}$ & $\begin{array}{l}43(31-52) \\
45(33-53)\end{array}$ \\
\hline $\begin{array}{l}\text { Rotem }{ }^{\circledast} \text { Delta } \\
\triangle A 10 \text { (EXTEM minus FIBTEM) [mm] } \\
\triangle M C F(\text { EXTEM minus FIBTEM) }[\mathrm{mm}]\end{array}$ & $\begin{array}{l}33(27-36) \\
36(29-37)\end{array}$ & $\begin{array}{l}24(19-35) \\
29(22-36)\end{array}$ & $\begin{array}{l}29(23-33) \\
28(23-35)\end{array}$ & $\begin{array}{l}30(24-36) \\
33(25-40)\end{array}$ \\
\hline $\begin{array}{l}\text { Multiplate }^{\circledast} \\
\text { TRAP-6 [AUC] (941-1563) } \\
\text { ADP [AUC] (534-1220) } \\
\text { ASPI [AUC] (745-1361) }\end{array}$ & $\begin{array}{l}518(241-819) \\
277(155-410) \\
378(116-800)\end{array}$ & $\begin{array}{l}430(279-676) \\
287(181-401) \\
365(126-673)\end{array}$ & $\begin{array}{l}367(236-744) \\
214(154-332) \\
289(95-797)\end{array}$ & $\begin{array}{l}555(276-809) \\
402(166-586) \\
461(184-1317)\end{array}$ \\
\hline
\end{tabular}

Rotem $^{\oplus}$ and Multiplate ${ }^{\oplus}$ results at days $1,4,7$ and 14 after admission to ICU (total $n=18$ ).

Point-of-Care testing over the course of ICU treatment. Rotem ${ }^{\bullet}$ results are shown for INTEM, EXTEM, FIBTEM and Delta (EXTEM minus FIBTEM). HEPTEM data are not depicted. Multiplate ${ }^{\oplus}$ results are displayed for the agonists thrombin receptor activator peptide 6 (TRAP-6), adenosine diphosphate (ADP) and arachidonic acid (ASPI) as Area under the Curve (AUC), respectively. Values are expressed as median and IQR. Units are displayed in square brackets and reference values in round brackets. Abbreviations: CT Clotting Time, CFT Clot Formation Time, A10 Amplitude 10 min after CT, MCF Maximum Clot Firmness, LI30 Lysis Index 30 min. 

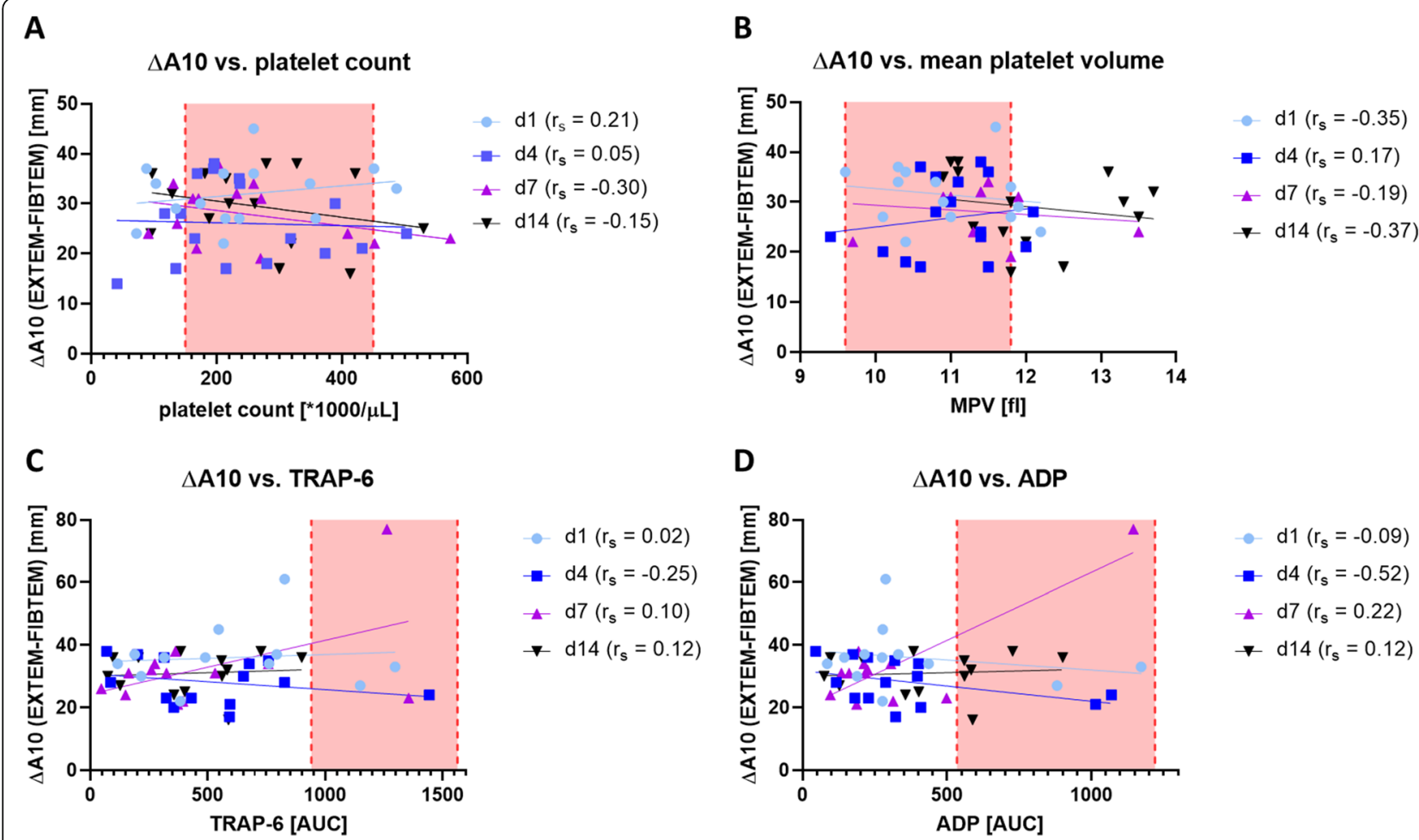

Fig. 1 Platelet aggregation ability by Multiplate ${ }^{\oplus}$. Correlation between $\triangle A 10$ (EXTEM minus FIBTEM) and platelet count, mean platelet volume and platelet aggregation ability (Multiplate ${ }^{\oplus}$ with TRAP-6 and ADP). a $\triangle A 10$ vs. platelet count. b $\triangle A 10$ vs. mean platelet volume. c $\triangle A 10$ vs. Multiplate ${ }^{\oplus}$ with agonist TRAP-6. $\mathbf{d} \triangle \mathrm{A} 10$ vs. Multiplate ${ }^{\oplus}$ with agonist ADP. Values are presented during the course of ICU stay for day $1(\bullet)$, day $4(\mathbf{\bullet})$, day 7 $(\boldsymbol{\Lambda})$ and day $14(\boldsymbol{\nabla})$ respectively. Spearman correlation coefficient is displayed by $r_{5}$. Reference values for platelet count, mean platelet volume, TRAP-6 and ADP are indicated by pink boxes

The primary aim of the current study was to identify and to evaluate the usefulness of POCT as readily available tools for the diagnosis of CAC. Our Rotem ${ }^{\odot}$ data pointed to a regular propagation phase of clot formation with strong clot firmness and no indication of hyperfibrinolysis during the entire course of ICU stay. These results are in line with prior COVID-19 Rotem ${ }^{\bullet}$ data demonstrating a significantly elevated MCF [11], [27]. Non-COVID-19 studies indicate that such an increased clot firmness could be associated with hypercoagulability [28], [29], [30].

Analysis of platelet function by Multiplate ${ }^{\circledR}$ point-of-care testing using agonists TRAP-6, ADP and ASPI detected a platelet aggregation ability well below the respective reference ranges. Multiplate ${ }^{\oplus}$ analysis could be biased by concomitant application of ASA in 15 patients, as well as a high percentage of ECMO therapy. However, different studies comparing blood from healthy donors and patients with daily ASA intake showed that ASA only reduces platelet aggregation after ASPI challenge, but not after incubation with TRAP-6 [31] or ADP [32]. Therefore, we believe that our Multiplate ${ }^{\oplus}$ results are ASA-independent. ECMO has been shown to reduce platelet aggregation ability after incubation with TRAP-6, ADP and ASPI [33]. We did not find significant differences in platelet aggregation between ECMO and non-ECMO patients. This indicates the presence of a COVID-19 induced, hypoactive platelet dysfunction irrespective of ECMO therapy. These findings differ from other studies in COVID-19 demonstrating increased platelet activation [34], [4]. This might result from the fact that a standardized definition of COVID-19 severity is missing and prior studies defined already severe COVID-19 by the sole requirement of oxygen supplementation.

Aiming to predict clinical events, there was no correlation between the results of POCT on day 1 and thromboembolic events or bleeding complications. During the course of ICU therapy thromboembolic events were more frequent with an elevated $\Delta \mathrm{A} 10>30 \mathrm{~mm}$. However, as Multiplate ${ }^{\oplus}$ and Rotem $^{\bullet}$ values were not correlated, the contribution of platelets to clot firmness in the majority of patients remains difficult to interpret. Our findings rather indicate that platelets may not predominantly contribute to the increased clot firmness.

Our study has some limitations, which should be carefully considered when interpreting the results. This is a 


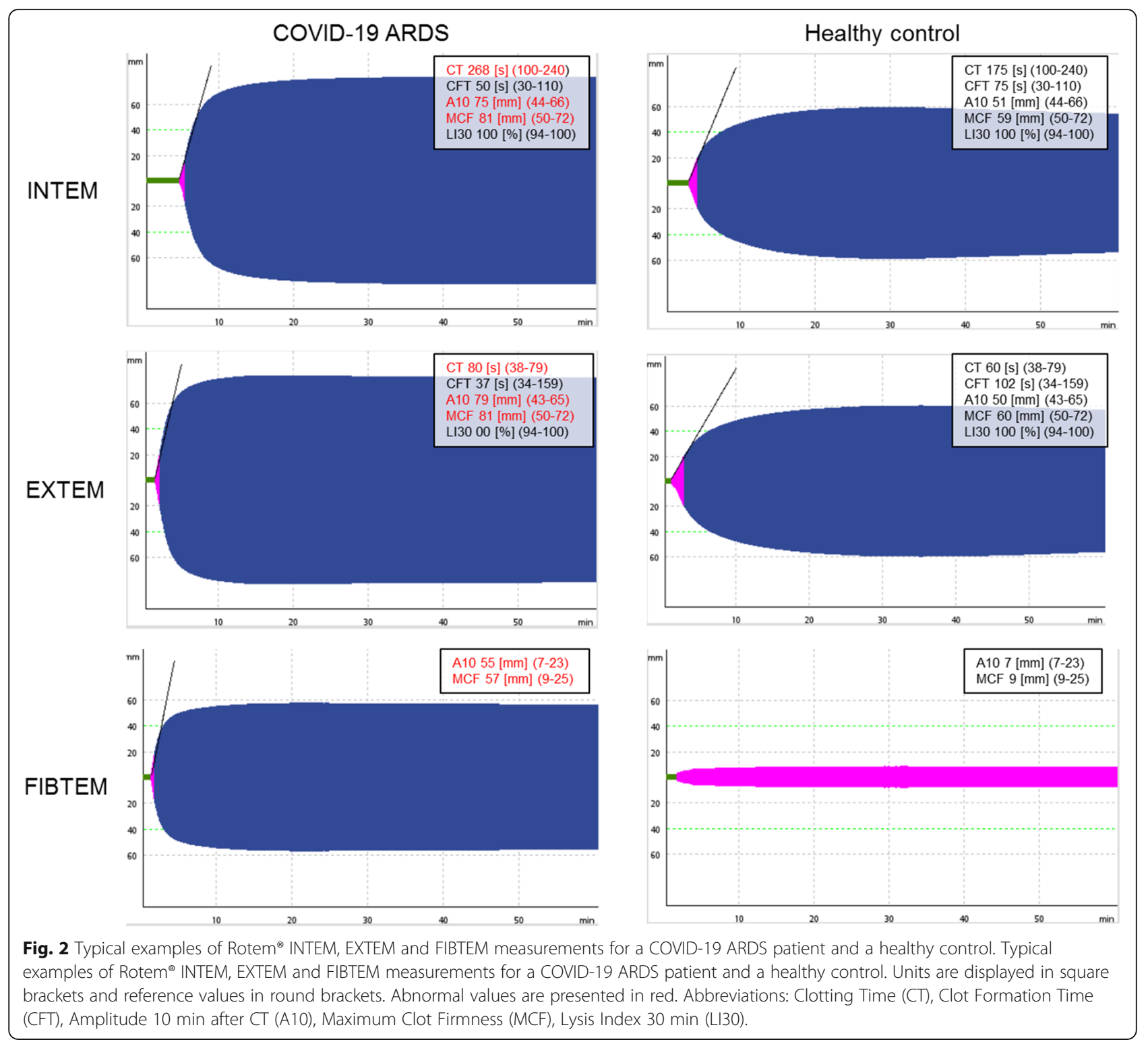

single center study in a highly selected patient population, analyzing data from a low number of patients with life-threatening illness. More than half of these patients received ECMO therapy, which is known to affect different aspects of hemostasis. Moreover, due the retrospective design additional groups with mild COVID-19 could not be included, as Multiplate ${ }^{\circ}$ and Rotem $^{\circ}$ POCT was not conducted in non-ICU patients or on a regular basis in non-COVID-19 ARDS patients, respectively.

\section{Conclusions}

In conclusion, monitoring hemostasis and early diagnosis of hemostatic complications in critically ill COVID19 patients remains challenging. In our patient population of COVID-19-induced ARDS, Rotem ${ }^{\circ}$ and Multiplate $^{\circ}$ testing were overall poorly related to hemostatic complications. Nevertheless, our results indicate hypercoagulability and platelet dysfunction, whereas a $\Delta \mathrm{A} 10>$ $30 \mathrm{~mm}$ over the course of therapy may indicate a higher risk of thromboembolic events.

\section{Abbreviations}

a: Alpha-angle; A10/A30: Amplitude 10 min and 30 min after CT; APACHE II Score: Acute Physiology And Chronic Health Evaluation II Score;

ADP: Adenosine diphosphate; ARDS: Acute respiratory distress syndrome; ASA: Acetylsalicylic acid; ASPI: Arachidonic acid; COVID-19: Coronavirus disease 2019; CFT: Clot formation time; CT: Clotting time; ICU: Intensive care unit; LI30/LI45/LI60: Lysis index $30 \mathrm{~min}, 45 \mathrm{~min}$ and $60 \mathrm{~min}$ after CT; LMWH: Low molecular weight heparin; MCF: Maximum clot firmness; ML: Maximum lysis; Multiplate ${ }^{\oplus}$ Impedance aggregometry; NSAID: Nonsteroidal anti-inflammatory drugs; PDMS: Patient data management system; POCT: Point-of-care testing; Rotem ${ }^{\oplus}$ Rotational thromboelastometry; RTPCR: Real-time reverse transcriptase polymerase chain reaction; SOFA Score: Sequential Organ Failure Assessment Score; TRAP-6: Thrombin 
receptor activator peptide 6; UFH: Unfractionated heparin; vV-ECMO: Venovenous extracorporeal membrane oxygenation

\section{Acknowledgements}

The investigators would very much like to thank all nurses, physicians and supporting staff of ICUs in the Department of Internal Medicine I and in the Department of Anesthesiology and Critical Care at University Hospital Wuerzburg for their dedication and relentless work in order to achieve the best possible outcome for their patients.

\section{Authors' contributions}

J. Herrmann planned the study, performed experiments, analysed data and wrote the manuscript. C. Lotz planned the study, analysed data and wrote the manuscript. Q. Notz and T. Schlesinger performed experiments, analysed data and critically revised the manu-script.P. Meybohm, H. Schulze, J. Stumpner, M. Kredel, M. Sitter, B. Schmid and P. Kranke ana-lysed data and critically revised the manuscript. The author(s) read and approved the final manuscript.

\section{Funding}

Open Access funding enabled and organized by Projekt DEAL and supported by the Open Access Publication Fund of the University of Wuerzburg.

\section{Availability of data and materials}

The datasets used and analysed during the current study are available from the corresponding author on reasonable request.

\section{Declarations}

\section{Ethics approval and consent to participate}

The institutional ethic board of the University of Wuerzburg approved the study $(63 / 20)$. The need for informed consent from individual patients was waived due to the context of sole retrospective chart review within standard care

\section{Consent for publication}

Not applicable.

\section{Competing interests}

The authors declare that they have no competing interests.

\section{Author details}

'Department of Anesthesiology and Critical Care, University Hospital Wuerzburg, Oberdürrbacherstr. 6, 97080 Wuerzburg, Germany. ${ }^{2}$ Institute of Experimental Biomedicine, Julius-Maximilians-University Wuerzburg, Wuerzburg, Germany.

\section{Received: 28 January 2021 Accepted: 17 May 2021}

\section{Published online: 02 June 2021}

\section{References}

1. Yang $X, Y u$ Y, Xu J, Shu H, Xia J, Liu H, et al. Clinical course and outcomes of critically ill patients with SARS-CoV-2 pneumonia in Wuhan, China: a singlecentered, retrospective, observational study. The Lancet Respiratory medicine. 2020

2. Klok FA, Kruip M, van der Meer NJM, Arbous MS, Gommers D, Kant KM, et al. Incidence of thrombotic complications in critically ill ICU patients with COVID-19. Thrombosis research. 2020;191:145-7.

3. Iba T, Connors JM, Levy JH. The coagulopathy, endotheliopathy, and vasculitis of COVID-19. Inflammation Research. 2020.

4. Manne BK, Denorme F, Middleton EA, Portier I, Rowley JW, Stubben C, et al. Platelet gene expression and function in patients with COVID-19. Blood. 2020;136(11):1317-29.

5. Nicolai L, Leunig A, Brambs S, Kaiser R, Weinberger T, Weigand M, et al. Immunothrombotic Dysregulation in COVID-19 Pneumonia is Associated with Respiratory Failure and Coagulopathy. Circulation. 2020.

6. Becker RC. COVID-19 update: Covid-19-associated coagulopathy. J Thromb Thrombolysis. 2020;50(1):54-67.

7. Spyropoulos AC, Levy JH, Ageno W, Connors JM, Hunt BJ, Iba T, et al. Scientific and Standardization Committee communication: Clinical guidance on the diagnosis, prevention, and treatment of venous thromboembolism in hospitalized patients with COVID-19. J Thromb Haemost. 2020;18(8):1859-65.

8. Adam Cuker EKT, Robby Nieuwlaat P, Angchaisuksiri C, Blair KE, Dane J, Davila M, DeSancho DL, Diuguid D, Griffin SR, Kahn, Frederikus A, Klok Al, Lee I, Neumann A, Pai M, Pai M, Righini KM, Sanfilippo D, Siegal M, Skara K, Touri EA, Akl, Imad Bouakl, Mary Ellene Boulos, Romina BrignardelloPetersen, Rana Charide, Matthew Chan, Karin Dearness, Andrea J. Darzi, Philipp Kolb, Luis E. Colunga-Lozano, Razan Mansour, Gian Paolo Morgano, Rami Z. Morsi, Atefeh Noori, Thomas Piggott, Yuan Qiu, Yetiani Roldan, Finn Schünemann, Adrienne Stevens, Karla Solo, Matthew Ventresca, Wojtek Wiercioch, RA, Mustafa, Holger J Schünemann. ASH 2020 guidelines on the use of anticoagulation in patients with COVID-19: Draft recommendations. Washington, DC: American Society of Hematology. Published October 8, 2020. http://www.hematology.org/COVIDguidelines. 2020.

9. Bikdeli B, Madhavan MV, Jimenez D, Chuich T, Dreyfus I, Driggin E, et al. COVID-19 and Thrombotic or Thromboembolic Disease: Implications for Prevention, Antithrombotic Therapy, and Follow-Up: JACC State-of-the-Art Review. J Am Coll Cardiol. 2020;75(23):2950-73.

10. Müller MC, Meijers JC, Vroom MB, Juffermans NP. Utility of thromboelastography and/or thromboelastometry in adults with sepsis: a systematic review. Crit Care (London England). 2014;18(1):R30.

11. Pavoni V, Gianesello L, Pazzi M, Stera C, Meconi T, Frigieri FC. Evaluation of coagulation function by rotation thromboelastometry in critically ill patients with severe COVID-19 pneumonia. J Thromb Thrombolysis. 2020;50(2):281-6.

12. Schulman S, Kearon C. Definition of major bleeding in clinical investigations of antihemostatic medicinal products in non-surgical patients. Journal of thrombosis haemostasis: JTH. 2005;3(4):692-4.

13. Kaatz S, Ahmad D, Spyropoulos AC, Schulman S. Definition of clinically relevant non-major bleeding in studies of anticoagulants in atrial fibrillation and venous thromboembolic disease in non-surgical patients: communication from the SSC of the ISTH. Journal of thrombosis haemostasis: JTH. 2015:13(11):2119-26.

14. Helms J, Tacquard C, Severac F, Leonard-Lorant I, Ohana M, Delabranche X, et al. High risk of thrombosis in patients with severe SARS-CoV-2 infection: a multicenter prospective cohort study. Intensive care medicine. 2020;46(6): 1089-98.

15. Al-Samkari H, Karp Leaf RS, Dzik WH, Carlson JCT, Fogerty AE, Waheed A et al. COVID-19 and coagulation: bleeding and thrombotic manifestations of SARS-CoV-2 infection. Blood. 2020:136(4):489-500.

16. Schmidt M, Hajage D, Lebreton G, Monsel A, Voiriot G, Levy D, et al. Extracorporeal membrane oxygenation for severe acute respiratory distress syndrome associated with COVID-19: a retrospective cohort study. The Lancet Respiratory medicine. 2020;8(11):1121-31.

17. Oude Lansink-Hartgring A, de Vries AJ, Droogh JM, van den Bergh WM. Hemorrhagic complications during extracorporeal membrane oxygenation The role of anticoagulation and platelets. J Crit Care. 2019;54:239-43.

18. Yang $X$, Yang Q, Wang Y, Wu Y, Xu J, Yu Y, et al. Thrombocytopenia and its association with mortality in patients with COVID-19. Journal of thrombosis haemostasis: JTH. 2020;18(6):1469-72.

19. Lippi G, Plebani M, Henry BM. Thrombocytopenia is associated with severe coronavirus disease 2019 (COVID-19) infections: A meta-analysis. Clinica chimica acta; international journal of clinical chemistry. 2020;506:145-8.

20. Henry BM, de Oliveira MHS, Benoit S, Plebani M, Lippi G. Hematologic, biochemical and immune biomarker abnormalities associated with severe illness and mortality in coronavirus disease 2019 (COVID-19): a metaanalysis. Clinical chemistry laboratory medicine. 2020;58(7):1021-8.

21. Jiang SQ, Huang QF, Xie WM, LV C, Quan XQ. The association between severe COVID-19 and low platelet count: evidence from 31 observational studies involving 7613 participants. Br J Haematol. 2020;190(1):e29-33.

22. Qu R, Ling Y, Zhang YH, Wei LY, Chen X, Li XM, et al. Platelet-to-lymphocyte ratio is associated with prognosis in patients with coronavirus disease-19. Journal of medical virology. 2020;92(9):1533-41.

23. Amgalan A, Othman M. Hemostatic laboratory derangements in COVID-19 with a focus on platelet count. Platelets. 2020:31(6):740-5.

24. Zou Y, Guo H, Zhang Y, Zhang Z, Liu Y, Wang J, et al. Analysis of coagulation parameters in patients with COVID-19 in Shanghai, China. Bioscience trends. 2020;14(4):285-9.

25. Wool GD, Miller JL. The Impact of COVID-19 Disease on Platelets and Coagulation. Pathobiol J ImmunoPathol Mol Cell Biol. 2021;88(1):15-27.

26. Berger JS, Kunichoff D, Adhikari S, Ahuja T, Amoroso N, Aphinyanaphongs $Y$, et al. Prevalence and Outcomes of D-Dimer Elevation in Hospitalized 
Patients With COVID-19. Arteriosclerosis, thrombosis, and vascular biology. 2020;40(10):2539-47.

27. Collett LW, Gluck S, Strickland RM, Reddi BJ. Evaluation of coagulation status using viscoelastic testing in intensive care patients with coronavirus disease 2019 (COVID-19): An observational point prevalence cohort study. Australian critical care: official journal of the Confederation of Australian Critical Care Nurses. 2020.

28. Tripodi A, Cappellini MD, Chantarangkul V, Padovan L, Fasulo MR, Marcon A, et al. Hypercoagulability in splenectomized thalassemic patients detected by whole-blood thromboelastometry, but not by thrombin generation in platelet-poor plasma. Haematologica. 2009;94(11):1520-7.

29. Campello E, Spiezia L, Zabeo E, Maggiolo S, Vettor R, Simioni P. Hypercoagulability detected by whole blood thromboelastometry (ROTEM $\left.{ }^{\circledR}\right)$ and impedance aggregometry (MULTIPLATE ${ }^{\oplus}$ ) in obese patients. Thrombosis research. 2015;135(3):548-53.

30. Akay OM, Ustuner Z, Canturk Z, Mutlu FS, Gulbas Z. Laboratory investigation of hypercoagulability in cancer patients using rotation thrombelastography. Medical oncology (Northwood, London, England). 2009;26(3):358-64.

31. von Pape KW, Dzijan-Horn M, Bohner J, Spannagl M, Weisser H, Calatzis A. [Control of aspirin effect in chronic cardiovascular patients using two whole blood platelet function assays. PFA-100 and Multiplate]. Hamostaseologie. 2007:27(3):155-60. quiz $61-2$.

32. Sabra A, Stanford SN, Storton S, Lawrence M, D'Silva L, Morris RH, et al. Assessment of platelet function in patients with stroke using multiple electrode platelet aggregometry: a prospective observational study. BMC Neurol. 2016;16(1):254

33. Balle CM, Jeppesen AN, Christensen S, Hvas AM. Platelet Function During Extracorporeal Membrane Oxygenation in Adult Patients. Frontiers in cardiovascular medicine. 2019;6:114

34. Hottz ED, Azevedo-Quintanilha IG, Palhinha L, Teixeira L, Barreto EA, Pão CRR, et al. Platelet activation and platelet-monocyte aggregate formation trigger tissue factor expression in patients with severe COVID-19. Blood. 2020;136(11):1330-41.

35. Taylor FB Jr, Toh CH, Hoots WK, Wada H, Levi M. Towards definition, clinical and laboratory criteria, and a scoring system for disseminated intravascular coagulation. Thromb Haemost. 2001;86(5):1327-30.

\section{Publisher's Note}

Springer Nature remains neutral with regard to jurisdictional claims in published maps and institutional affiliations.

Ready to submit your research? Choose BMC and benefit from:

- fast, convenient online submission

- thorough peer review by experienced researchers in your field

- rapid publication on acceptance

- support for research data, including large and complex data types

- gold Open Access which fosters wider collaboration and increased citations

- maximum visibility for your research: over $100 \mathrm{M}$ website views per year

At $\mathrm{BMC}$, research is always in progress.

Learn more biomedcentral.com/submissions 